\title{
Analysis of Fatty Acyl Groups of Diacyl Galactolipid Molecular Species by HPLC/ESI-MS with In-source Fragmentation
}

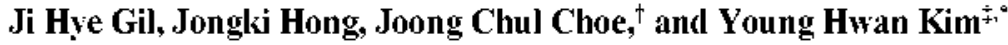 \\ Hazardous Substance Research Team, Korea Basic Science Institute, Seoul 126-701. Korea \\ -Department of Chemistry, Chiversity of Sum on, Suw $4+10-600$. Korea \\ -Proteome Analvsis Team, Korea Basic Science Institute. Daejeon 305-806. Korea \\ Received.April 4. 2003
}

\begin{abstract}
The structures of molecular species of galactolipids. such as monogalactosyl diacylglycerol (MGDG) and digalactosyl diacylglycerol (DGDG). isolated from wheat flour have been investigated using negative-ion electrospray ionization (ESI) mass spectrometry interfaced with high perfornance liquid cluronatography (HPLC). According to the result of HPLC analysis. MGDG and DGDG were found to consist of mixtures of five and four molecular species, respectively. The galactolipids have been also analyzed to deternine their fatty acid compositions, using HPLC/ESI-MS combined with in-source (or cone voltage) fragmentation. HPLC/ ESI-MS is very useful for one-step analysis of mixtures of galactolipids with a small sample quantity. Especially, the carboxylate anions produced in in-source fragmentations of the negative-ion of each component separated by HPLC provide valuable information on the composition of its fatty acyl chains.
\end{abstract}

Key Words : Galactolipids. Electrospray ionization (ESI). Mass spectrometry. High performance liquid chromatography (HPLC). In-source fragmentation

\section{Introduction}

The benzene-extractable lipids of bleached wheat flour have at least two galactosyl glyceride compounds that were identified as monogalactosyl diacylglycerol (MGDG) and digalactosyl diacylglycerol (DGDG) by the characterization of the carbohydrate moiety of these lipids. ${ }^{1}$ These galactolipids. composed of a major class of membrane lipids in plants. are associated largely with photosynthetic tissues. ${ }^{2-5}$ Galactolipids with unique structure and function are located in heterocyst cell walls and have been isolated from various organisms with pharmacological activity or unique structural features. ${ }^{6}$ Plant seeds have a relatively low content of galactolipids compared with their content of phospholipids and neutral lipids. and the galactolipids account for only about $3 \%$ of the total lipids of all seeds examined. ${ }^{7}$ Each of the two major galactolipid classes. MGDG and DGDG. is composed of various molecular species differing in chain length and degree of unsaturation of their fatty acyl groups. ${ }^{8}$

The isolation of single molecular species from plant sources is quite difficult due to the complexity of these mixtures and the similarities in chemical structures. As galactolipids are thermally labile and nonvolatile. previous ionization methods such as electron ionization (EI) or chemical ionization (CI) are unsuitable. The development of soft ionization techniques for mass spectrometry has permitted the analy ses of a wide variety of plant compounds. Electrospray ionization mass spectrometry (ESI-MS) is used

\footnotetext{
Author to whom correspondence should be addressed. Tel: +82-42-865-3433; Fax: +82-42-865-3419; e-mail: yhkinia kbsi.re.kr
}

primarily to analyze proteins. which are not only difficult to ionize under any circumstances. but also have molecules too large to be analyzed with a conventional mass spectrometer. Recently. ESI-MS has been widely applied to the analysis of glycoproteins. ${ }^{9}$ oligonucleotides. ${ }^{10.11}$ oligosaccharides. ${ }^{12.13}$ drugs and dnug metabolites. ${ }^{1+}$ environmental contaminants. ${ }^{15.16}$ and numerous other types of compounds. ${ }^{17}$ The combination of the fast atom bombardment (FAB) ionization method and tandem mass spectrometry (MS/MS) for the analysis of mixtures has largely improved the structural characterization of several high-mass lipids at the molecular species level. ${ }^{+18-24}$ This teclnique is uniquely suited for the characterization of compounds featuring a long alkyl group and a localized polar moiety. ${ }^{4.25}$ Although the complete structural information for lipids can be obtained by fast atom bombardment tandem mass spectrometry (FAB-MS/MS) electrospray ionization offers several advantages over this ionization technique. including lower background signals due to the absence of matrix ions. longer lasting and stable primary ion currents. ease of sampling and compatibility with liquid chromatographs. ${ }^{2 i-3]}$

High performance liquid chromatography mass spectrometry (HPLC/MS) has great potential for the on-line analysis of lipids. A few successful analyses using HPLC/MS sy'stems have been described providing separation of phospholipid molecular species ${ }^{32-34}$ Reverse-phase HPLC of plant galactolipids. however. has been applied only in a few cases. Separation by reversed-phase chromatography was especially suitable for the partitioning of molecular species within a lipid class. ${ }^{35.3 \%}$

In the present study, we report the analytical method for the determination of fatty acyl groups of the molecular species present in complex mixtures of MGDG and DGDG. 
using HPLC/ESI-MS combined with in-source fragmentation in the negative-ion mode.

\section{Experimental Procedures}

Material. Monogalactosyl diacylglycerol [1.2-diacyl-3-O( $\beta$-D-galactopyranosy l)-sn-glycerol : MGDG] and digalactoșy l diacy lglycerol [1 2-diacy l-3-O-( $\alpha$-D-galactopy ranosy l$(1 \rightarrow 6)-O-\beta$-D-galactopyranosyl)-sn-glycerol : DGDG] from whole wheat flour were purchased from Sigma Chemical Co.(St. Louis. MO. USA). Information on the fatty acid composition of each molecular species in mixtures of MGDG and DGDG was not available from the commercial source. All other reagents were of analytical grade.

Liquid Chromatography. The liquid chromatography was carried out with a LC- $10 \mathrm{AD}$ solvent delivery module (Shimadzu. Kýoto. Japan) and Rheodyne 7520 injector with a $0.5 \mu \mathrm{L}$ sample loop (Rheodyne. CA. USA). The separations were performed on a microcolumn $1.0 \mathrm{~mm}$ i.d. $\times 250 \mathrm{~mm}$ Length CapcellPak $\mathrm{C}_{18}$ (Shiseido. Japan). The injection volume was $0.5 \mu \mathrm{L}$ of sample with a concentration of $50 \mathrm{ng} /$ $\mu \mathrm{L}$. The flow rate was $50 \mu \mathrm{L} / \mathrm{min}$ and a mobile phase consisted of methanol water and acetonitrile (90.5: $7: 2.5$. $\mathrm{v} / \mathrm{v} / \mathrm{v})$ was used ${ }^{37}$ The UV detector was operated at $205 \mathrm{~nm}$.

Mass Spectrometry. The mass spectrometry was carried out with a VG Quattro triple quadrupole mass spectrometer (Fisons Instruments. VG Organic. Altrincham. UK) equipped with a pneumatically assisted electrospray ionization source. Nitrogen was used both as a nebulizing gas and drying gas at flow rates of $500 \mathrm{~L} / \mathrm{h}$ and $15 \mathrm{~L} / \mathrm{h}$. respectively. The capillary voltage was $-2.26 \mathrm{kV}$ (in the negative-ion mode) with a source temperature of $80^{\circ} \mathrm{C}$. A voltage applied to the orifice of the instrument. also known as the cone voltage. created a potential difference between the skimmer lens and cone of Quattro source. The cone voltage was set to a soft value of $20 \mathrm{eV}$ to detect deprotonated molecular ion $[\mathrm{M}-\mathrm{H}]^{-}$of the separated molecular species of galactolipids in the effluent. On the other hand. in the in-source fragmentation experiment. the cone voltage was increased to a higher energetic value $(60 \mathrm{eV})$ to promote fragmentation in the source. A full scan mass spectrum was acquired over the mass range between $m z 200$ and 800 for MGDG and between $m: 200$ and 1000 for DGDG. The scan time was $3 \mathrm{~s}$ and the interscan time $1 \mathrm{~s}$. Data handling was performed with a VG MassLựx data șystem.

\section{Results and Discussion}

The structures of the galactolipids isolated from wheat flour are shown in Figure 1. The two non-polar fatty acyl chains $\left(\mathrm{R}_{1}\right.$ and $\left.\mathrm{R}_{2}\right)$ are attached at the $s n-1$ and $s n-2$ positions of the glycerol backbone with a polar head group such as monogalactose and digalactose. Since galactolipids differ mainly in the chain length and the position and degree of unsaturation of fatty acyl groups. it is difficult to separate and purify a naturally occurring mixture of galactolipids. Therefore. galactolipids are analyzed using a mixture in
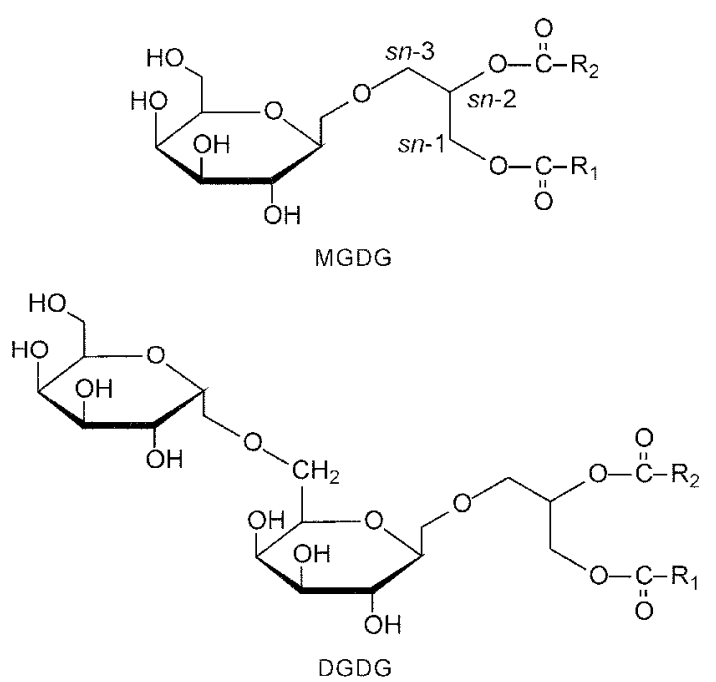

Figure 1. Structures of monogalactosyl diacylglycerol (MGDG) and digalactosyl diacylglycerol (DGDG). The acyl groups designated $\mathrm{R}_{1}$ and $\mathrm{R}_{2}$ are attached at the $s h-1$ and $s n-2$ positions of the glycerol backbone, respectively.
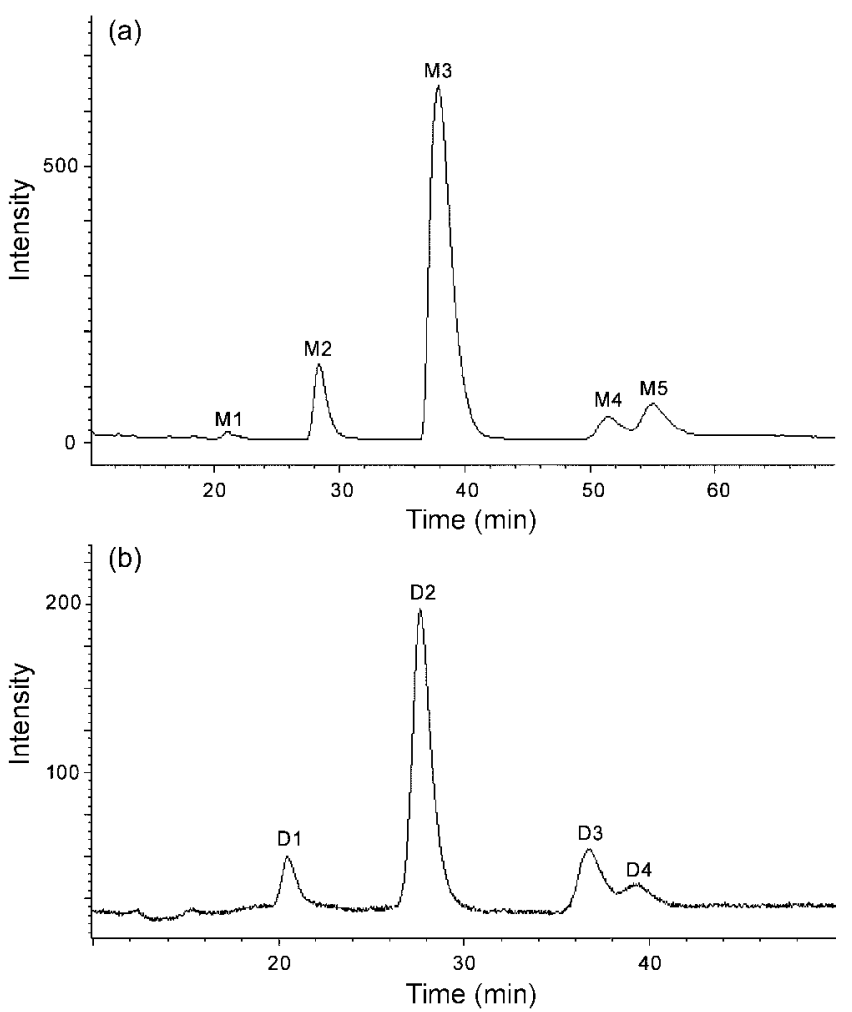

Figure 2. Separation of the molecular species of (a) MGDGs and (b) DGDGs extracted from wheat flour by reverse-phase HPLC.

itself or after separation through complex multistep procedures. The analysis of molecular species has usually been performed in a series of steps. which include partial hydrolysis. derivative formation. and/or a combination of several different types of chromatographic procedures. However, we separated the molecular components in a mixture with reverse-phase HPLC system. The molecular 


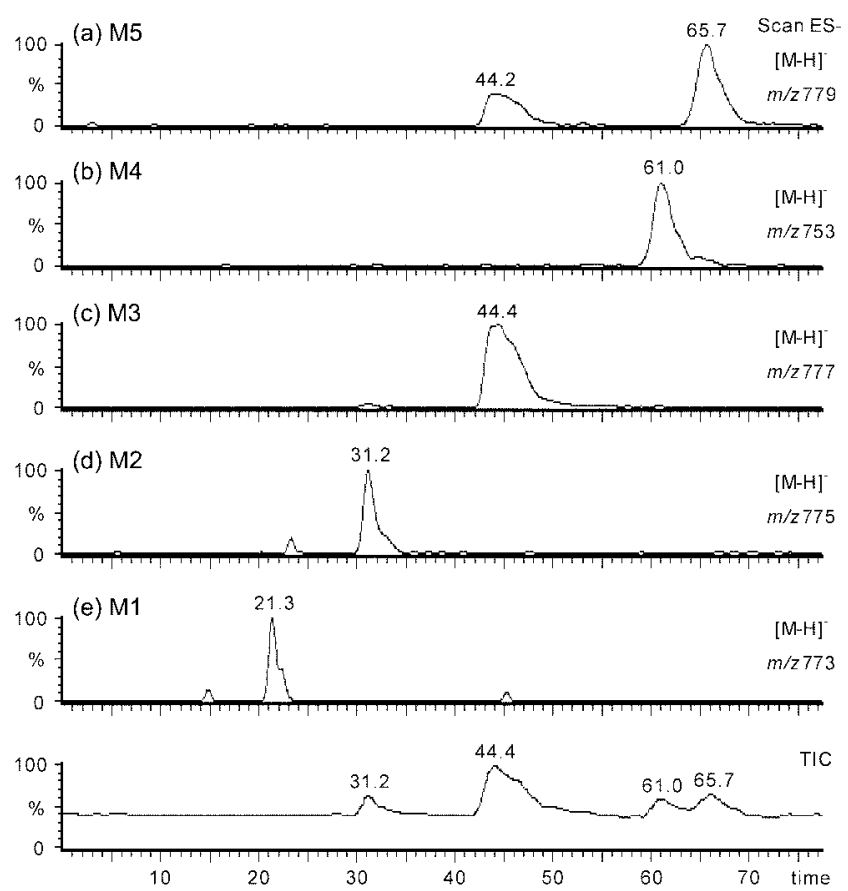

Figure 3. Extracted ion chromatograms of deprotonated molecular ions $[\mathrm{M}-\mathrm{H}]^{-}$obtained at cone voltage $20 \mathrm{eV}$ for five molecular species of MGDG, which were separated in reverse-phase HPLC and total ion chromatogram (TIC).

species in each lipid class was identified as shown in Figure 2. According to previous reports (37.38). UV detection in HPLC separation depends on their double-bond number. According to the result of the HPLC analysis. DGDG elutes faster than MGDG and within both galactolipid classes the order of elution of molecular species was constant and entirely dependent on the composition of the fatty acyl group of the molecular species. The chromatograms in Figure 2 show the peaks of five molecular species for MGDG and four molecular species for DGDG. respectively.

Figure 3 shows the total ion chromatogram and extracted ion chromatogram of $[\mathrm{M}-\mathrm{H}]^{-}$ion of each MGDG species obtained at cone voltage (CV) of $20 \mathrm{eV}$ using the reversephase HPLC interfaced with electrospray ionization technique in the negative-ion mode. The MGDG was separated into five components differing by the composition of the fatty acyl groups. The total ion chromatogram in Figure 3 is very similar to the one shown in Figure 2(a). The extracted ion chromatogram of each deprotonated molecular ion [M$\mathrm{HJ}]^{-}$at $m z 779.777 .775,773$ and 753 corresponding to the molecular species of MGDG is shown in the same figure.

ESI mass spectra of the components of MGDG are shown in Figure 4. The major peaks observed in the spectra were assigned to the deprotonated molecular ions $[\mathrm{M}-\mathrm{H}]^{-}$of individual MGDG molecular species. The molecular ion peaks observed at $m z$ 779, 777. 775.773 and 753 in ESI mass spectra indicate that each MGDG species has total fatty acid composition of C36:3. C36:4, C36:5. C36:6 and $\mathrm{C} 34: 2$, respectively. In addition, the chlorine adducted ions $[\mathrm{M}+\mathrm{Cl}]^{-}$of the components were also observed at $m z 815$. 813.811. 809 (not shown in Figure 4) and 789. Their mass

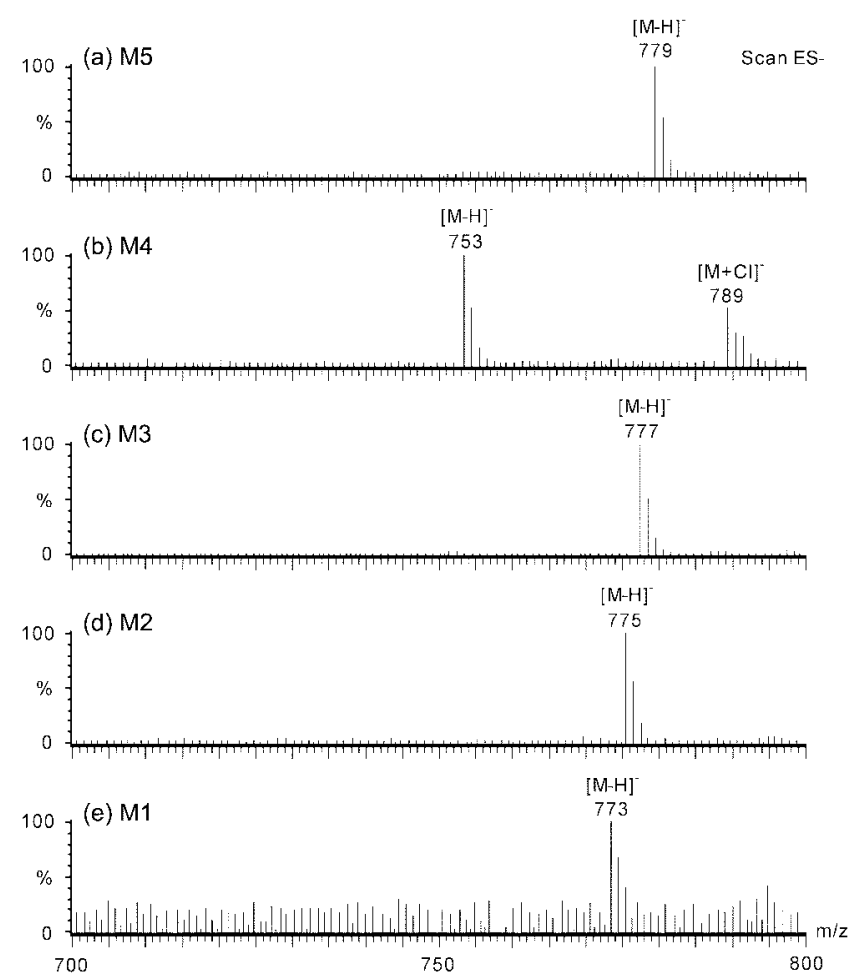

Figure 4 . ESI mass spectra obtained for the molecular species eluting at $65.7,61.0,44.4,31.2$ and $21.3 \mathrm{~min}$ in TIC of MGDG shown in Fig 3.: (a) M5(C 36:3) (b) $\mathrm{M} 4(\mathrm{C} 34: 2$ ) (c) $\mathrm{M} 3(36: 4)$ (d) $\mathrm{M} 2(\mathrm{C} 36: 5)$ and (e) $\mathrm{Ml}(\mathrm{C} 36: 6)$ (carbon number: number of doublebond $)$.

spectra provide only information on total fatty acid composition but no information on the double-bond positions and the composition of each fatty acyl chain.

In our previous reports $(4,25)$. FAB in combination with tandem mass spectrometry (MS/MS) has been demonstrated for the structural analysis of the molecular species of galactolipids. The positions of the double bonds in the fatty acid chains could be determined from a series of chargeremote fragmentation occurring along the fatty acid chains. In this work. we obtained the CID spectnum of each component by using an in-source fragmentation teclunique for the structural analysis. The most suitable cone voltage was determined by observing the carboxylate ion informative on the composition of each fatty acyl group. The spectra obtained by the in-source fragmentation of individual components at a cone voltage of $60 \mathrm{eV}$ are shown in Figure 5. From the C18:1 and C18:2 carboxylate anions observed at $m z 281$ and 279. it was concluded that the major component ( $m: z 79$ ) of MGDG with total fatty acid composition of $\mathrm{C} 36: 3$ contained $\mathrm{C} 18: 1$ and $\mathrm{C} .18: 2$ fatty acyl groups. The results for the compositions of the fatty acyl groups obtained for the other components are summarized in Table 1. Based on the results. we concluded that the highly' unsaturated species with the same carbon length among the species was first eluted and then other molecular species eluted in order of decreasing unsaturation. However. for two species with the respective compositions of $\mathrm{Cl} 16: 0 / \mathrm{Cl} 8: 2$ and $\mathrm{Cl}$ : $2 / \mathrm{C} 18: 1$ (carbon number : number of double-bond). 

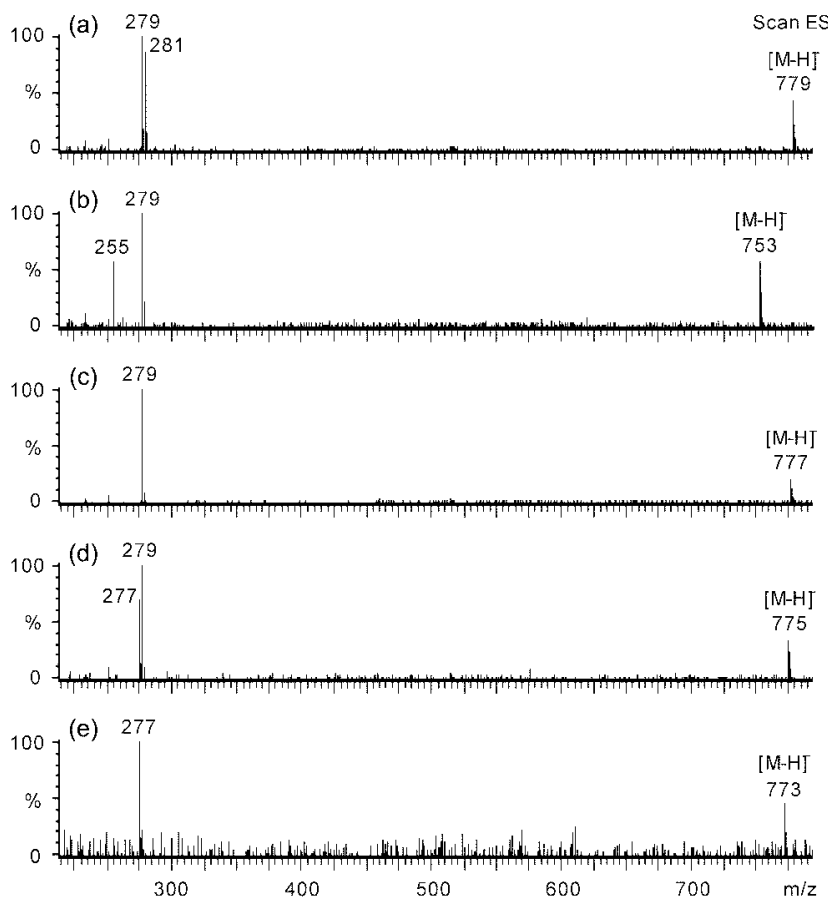

Figure 5. Mass spectra obtained by in-source fragmentation of MGDG species at CV $60 \mathrm{eV}$ (a) M5(C18:2, C18:1) (b) M4(C16:0, $\mathrm{C} 18: 2)$ (c) $\mathrm{M} 3(\mathrm{C} 18: 2, \mathrm{Cl} 18: 2)$ (d) $\mathrm{M} 2(\mathrm{Cl} 18: 3, \mathrm{C} 18: 2)$ and (e) $\mathrm{MI}(\mathrm{C} 18: 3, \mathrm{Cl} 18: 3)$.

Table 1. Fatty acid compositions of MGDG and DGDG molecular species isolated from whole wheat flour

\begin{tabular}{|c|c|c|c|c|}
\hline Lipid class & Species & MW & {$[\mathrm{M}-\mathrm{H}]^{-}$} & $\begin{array}{c}\text { Structure of fatty } \\
\text { acyl groups }\end{array}$ \\
\hline \multirow[t]{5}{*}{ MGDG } & $\mathrm{Ml}$ & 774.6 & 773.4 & $\mathrm{Cl} 18: 3 / \mathrm{Cl} 18: 3$ \\
\hline & $\mathrm{M} 2$ & 776.6 & 775.4 & $\mathrm{C} 18: 2 / \mathrm{Cl} 8: 3$ \\
\hline & Mi & 778.6 & 777.4 & $\mathrm{C} 18: 2 / \mathrm{C} 18: 2$ \\
\hline & M4 & 754.6 & 753.5 & $\mathrm{Cl} 16: 0 / \mathrm{C} 18: 2$ \\
\hline & M5 & 780.6 & 779.6 & C $18: 2 / \mathrm{C} 18: 1$ \\
\hline \multirow[t]{4}{*}{ DGDG } & Dl & 9386 & 937.5 & $\mathrm{C} 18: 2 / \mathrm{Cl} 18: 3$ \\
\hline & $\mathrm{D} 2$ & 940.6 & 939.5 & $\mathrm{C} 18: 2 / \mathrm{C} 18: 2$ \\
\hline & D3 & 9166 & 915.5 & $\mathrm{Cl} 6: 0 / \mathrm{C} 18: 2$ \\
\hline & D4 & 942.6 & 941.5 & C 18:2/C18:1 \\
\hline
\end{tabular}

"The fatty acyl groups are symbolized by the convention. carbon number: number of double-bond.

the molecular species with shorter fatty acyl chain eluted more rapidly than species with longer fatty acyl chain.

Figure 6 shows the total ion chromatogram of ESI mass spectrum of DGDG obtained at cone voltage of $20 \mathrm{eV}$ and the extracted ion chromatogram of the deprotonated molecular ion of each component present in a mixture of DGDG. The chromatographic pattern of DGDG is very similar to that of MGDG. The molecular mass of individual components of DGDG eluted at 33.3.43.4. 55.8 and 59.2 minutes were identified as 938.940 .916 and $942 \mathrm{Da}$. respectively.

The negative-ion ESI mass spectra of D1. D2. D3 and D4 corresponding to each components of DGDG in Figure 6 are shown in Figure 7. The dominant ions observed in each ESI mass spectrum are the deprotonated molecular ion $[\mathrm{M}-\mathrm{H}]^{-}$
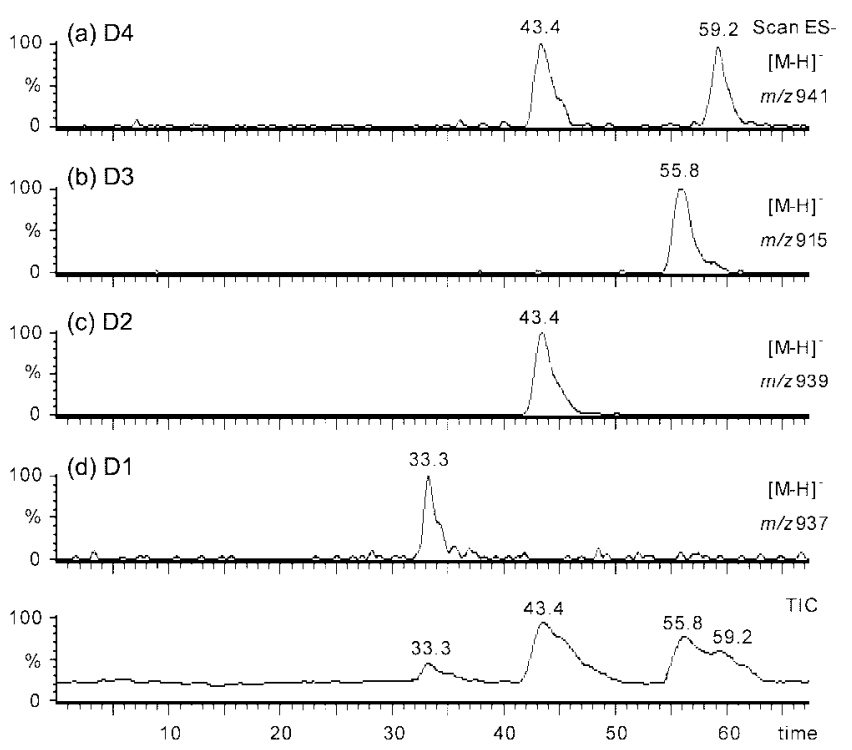

Figure 6. Extracted ion chromatograms of deprotonated molecular ions $[\mathrm{M}-\mathrm{H}]^{-}$obtained at cone voltage $20 \mathrm{eV}$ for four molecular species of DGDG, which were separated in reverse-phase HPLC and total ion chromatogram (TIC).
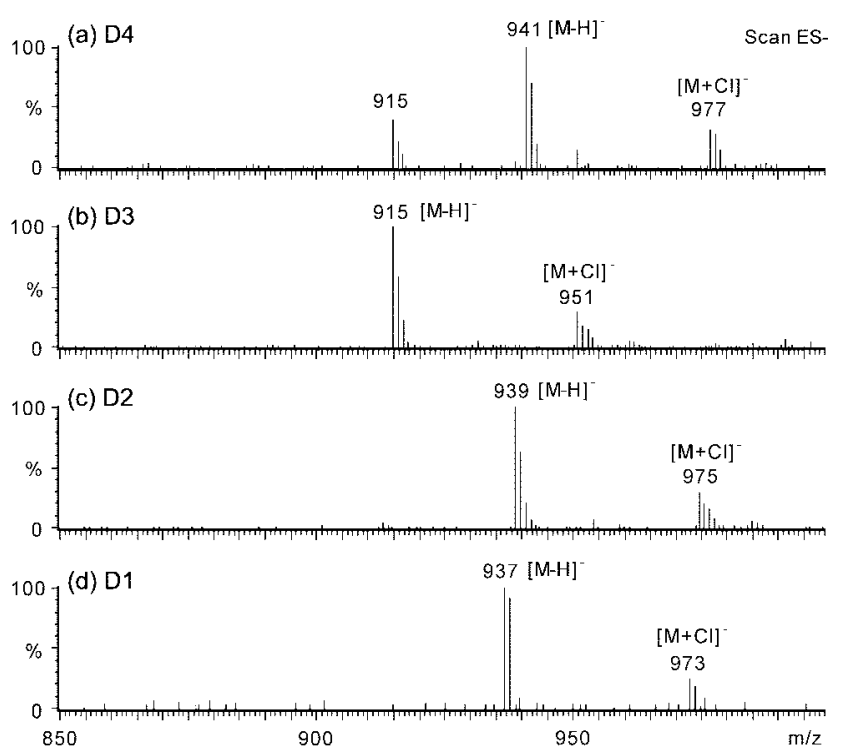

Figure 7. ESI mass spectra obtained for the molecular species eluted at $59.2,55.8,43.4$ and $33.3 \mathrm{~min}$ in TIC of DGDG shown in Fig 6; (a) D4(C36:3) (b) D3(C34:2) (c) D2(C36:4) and (d) $\mathrm{DI}(\mathrm{C} 36: 5)$

and chlorine adducted ion $[\mathrm{M}+\mathrm{Cl}]^{-}$of each component. Thus. the mixture of DGDG was composed of four molecular species containing total fatty acid composition of C36.5. C36:4. C34:2 and C36:3. respectively.

The in-source fragmentation of each component at cone voltage of $60 \mathrm{eV}$ yielded the carboxy late anions corresponding to the fatty acyl groups as shown in Figure 8. The ions produced by in-source fragmentation of the $[\mathrm{M}-\mathrm{H}]^{-}$ion at $m z 941$ indicated intense peaks at $m: 279(\mathrm{Cl} 18: 2)$ and $m z$ 281 (C.18:1) in the acyl region of the mass spectrum. Base on the results summarized in Table 1 , the components of DGDG isolated from wheat flour had two fatty acyl groups 

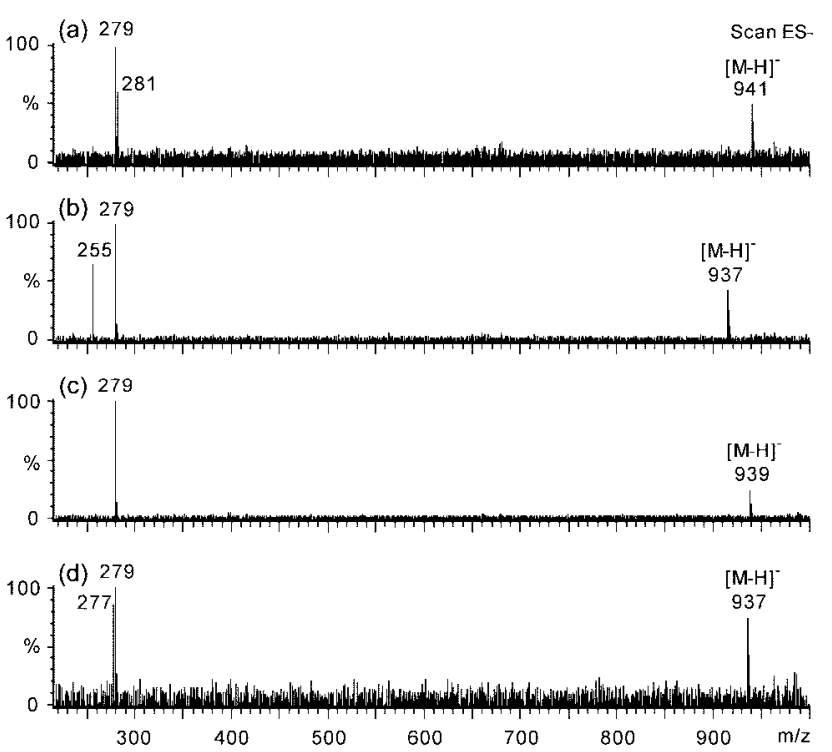

Figure 8. Mass spectra obtained by in-source fragmentation of DGDG species at CV $60 \mathrm{eV}$ (a) D4(C 18:2, C18:1) (b) D3(Cl6:0, C $18: 2)$ (c) D2(C18:2, C18:2) and (d) Dl(C18:3, C18:2).

exactly the same as those of MGDG except for the absence of $\mathrm{C} 18: 3 / \mathrm{C} 18: 3$ component. This component in DGDG may not be detectable due to its extremely small quantity. This similarity between the fatty acyl groups of MGDG and DGDG may owe to a common biosythesis pathway of galactolipids involving successive acylations of glycerol-3phosphate at the $s n-1$ and $s n-2$ positions of glycerol backbone. This is followed by dephosphorylation to 1.2diacylglycerol. which finally involves a transfer of galactose (or digalactose) from a galactose (or digalactose) donor at the $s n-3$ position. ${ }^{39}$

In the negative-ion mode. all classes of galactolipids underwent similar fragmentation processes. The principal product ions due to the cleavage of the acyl moieties with negative charge retention on the free fatty acids provide the information about the fatty acid composition of each component. The less prominent ions were also observed due to the elimination of $\mathrm{RCOO}^{-}$from the $[\mathrm{M}-\mathrm{H}]^{-}$ion. In addition to providing information on the composition of the two acyl groups. the negative-ion in-source fragmentation also allowed us to identify the polar head group by difference between the molecular masses of the two fatty acids and the total molecular mass.

The HPLC/ESI-MS with in-source fragmentation in the negative-ion mode provides a highly sensitive tool for determination of fatty acid compositions of galactolipids at the level of their individual molecular species. For routine analyses. HPLC/ESI-MS offers advantages. such as clear-cut separations. simple. rapid and cost-effective analyses and consumption of a small amount of sample. over the conventional HPLC analysis. The positions of double bonds cannot be determined. whereas the number of double-bonds in the fatty' acyl chains can be identified. However this problem can be solved by using high-energy collision-induced decomposition (CID) techuiques with $\mathrm{FAB}$ as reported previously ${ }^{19.21 .25}$ But HPLC/ESI-MS combined with insource fragmentation techniques in the negative-ion mode can provide insight into the fatty acid composition of each galactolipid species present in the mixture without the use of tandem mass spectrometric techniques (MS/MS).

\section{References}

1. Carter. H. E: MeCluer. R. H. Slifer, E. D. J. Am. Chem. Soc. 1956. 78. 3735 .

2. Murakami. N.: Morimoto. T.: Ueda. T.: Nagai. S.: Sakakibara. J.: Yamada. N. Phrochemistry 1992.31.2641.

3. Heinz, E.: Rullkötter, J.: Budzikiewicz, H. Hoppe-Sevier's Z. Phusiol. Chem. 1974. 355.612.

4. Kim. Y. H.: Yoo. J. S.; Kim. M. S. J. Mass Spectrom 1997, 32. 968

5. Siebertz. H. P.: Heirz. E.: Linscheid. M.: Joyard. J.: Donce. R. Eur. J. Biochent 1979. J01. 429.

6. Murakami. N.: Shirahashi, H. Nagatsu, A.; Sakakibara. J. Chent. Pham Bull. 1993. H. 1177.

7. Kates. M. In Handbook of Lipid Reszarch: Glycolipids. Phosphoglycolipids, and Sulfoglycolipids: Kates. M.. Ed.: Plenum Press: New York. U. S. A.. 1990: Vol. 6. p 235.

8. Cho. S. H: Thompson. G. A. J. Biol. Chem. 1987. 262.7586.

9. Kawasaki. N.; Ohta, M.: Hyuga, S.; Hashimoto, O.: Hayakawa, T. Anal Biochem 1999. 269,297.

10. Krahmer. M. T; Johnson, Y. A.: Walters, J. J.; Fox, K. F.: Fox. A.; Nagpal. M. Anal. Chem. 1999. 71.2893.

11. Kapur. A.: Beck. J. L.: Sheil. M. M. Rapid Commm. Hass Spectron 1999. 13. 2489.

12. Mo. W.: Sakamoto, H.; Nishikawa, A.; Kagi, N.; Langridge. J. I:; Shimonishi, Y: Takao, T. And. Chem 1999. 71. 4100.

13. Risberg, A.: Masoud, H.: Martin, A.; Richards, J. C:; Moson. E. R.: Schweda. E. K. H. Eur. J Biochem. 1999. 261. 171.

14. Lhoëst. G.: Zey. T.: Verbeeck. R. K.: Wallemacq. P.: Maton. N.: DeHoux. J. P.: Latinne D. J. Hass Spectron. 1999. 3+. 28.

15. Castillo, M: Alonso. M. C.: Riu, J.: Barcelo, D. Eniront. Sci. Techol. 1999.33. 1300.

16. Magnuson. M. L.: Urbansky: E. T.; Kelty, C. A. Anal. Chem. 2000. 72. 25 .

17. Mauri. D.: Migliazza. B.: Pietta. P. J. Mass Spectron. 1999. 34. 1361.

18. Kim. Y. H.: Yoo, J. S.; Kim, M. S. Bull. Konean Chent. Soc. 1997. 18.874.

19. Kim. Y. H.: Choi. J.-S.: Yoo, J. S.: Park, Y.M.; Kim, M. S. Anal. Biochem. 1999. 267.260.

20. Kim. Y. H.: Han. S.-Y: Cho. S.-H.: Yoo. T. S.: Thon. G.-T. Rapid Conmum. Mass Spectront 1999.13.481

21. Kim. Y. H; Choi, J.-S.: Hong, J; Yoo, J. S.; Kim, M. S. Lipids 1999. 34,847

22. Limb. J.-K.: Kim. Y. H.: Han, S.-Y.: Jhon. G.-J. J. LipidRes. 1999. 40. 2169.

23. Park. H. S.: Lee. S. Y:: Kim. Y. H.: Kim. T. Y.: Lee. S. J.: Choi. M.U. Biochin. Biophs Acta 2000. 1484. 151.

24. Kim. Y. H: So. K.-Y.: Limb. J.-K J Jhon. G.-J; Han, S.-Y. Rapid Commun. Mass Spectrom 2001, 1, 2230.

25. Kim. Y. H.: Gil. J. H.: Hong. J.: Yoo, J. S. Aficochem J. $\mathbf{2 0 0 1 , 6 8 .}$ 143.

26. Harrata. A. K.: Domelsmith. L. N.: Cole. R. B. Biol Mass Spectron. 1993. 22.59.

27. Griffiths, W. J.: Brown. A.; Reimendal. R: Yang, Y.: Zhang, J. Sjovall. J. Rapid Commun. Hass Spectrom. 1996, 10. 1169.

28. Brügger. B.: Erben, G; Sandhoff, R: Wieland, F. T; Lehmann. W. D. Proc. Natl Acad Sci. LSt 1997. 94. 2339.

29. Lee. M. H.: Yoo. J. S.: Lee. G. H. Rapid Commm. Mass Spectront 1998.12.17099.

30. Smith. P. B. W. Snvder. A. P. Harden. C. S. Anal Chent 1995 
67,1824

31. Ohashi, Y. In Electrosprav Ionization Mass Spectrometry Cole R. B. Ed.: John Wiley \& Sons. Inc.: New York. U. S. A.. 1997: p 459.

32. Valeur. A.: Michelsen. P: Odham. G. Lipids 1993. 28.255.

33. Vernooij. E. A. A. M.: Bosch. I. I. K.: Crommelin. D. J. A. Rapid Contmuth Mass Spectrom. 1998, I2.83.

34. Kim, H. Y. Wang. T. L.: Ma, Y. C. Anal them, 1994, 66, 3977.

35. Heemskerk. J. W. M.: Bögemann. G.: Scheijen. M. A. M.:
Wintermans. J. F. G. M. Anal Bichent 1986, 15t. 85.

36. Lynch, D. V: Gundersen. R. E.: Thompson, G. A. Plant Plysiol. 1983. 72.903

37. Demandre. C.: Tremolieres. A.: Justin. A.: Mazliak. P Phrochemismy 1985. 24. 481 .

38. Patton, G. M.: Fasulo, J. M: Robins, S. J. J. Lipid Res. 1982, 23. 190.

39. Joyard, J Douce. R. In The Biochemisty of Plants: Stumpf. P. K. Ed.: Academic Press: San Diego. U. S. A.. 1987. 